\title{
SOLID DISPERSION TECHNIQUE TO ENHANCE THE SOLUBILITY AND DISSOLUTION OF FEBUXOSTAT AN BCS CLASS II DRUG
}

\section{CHRISTOPHER VIMALSON ${ }^{*}$, S. PARIMALAKRISHNAN ${ }^{2}$, N. S. JEGANATHAN ${ }^{1}$, S. ANBAZHAGAN ${ }^{1}$}

${ }^{*}$ Department of Pharmacy, Annamalai University, Chidambaram, Tamil Nadu, India, ${ }^{1}$ Department of Pharmaceutics, Surya School of Pharmacy, Vikravandi, Villupuram, Tamil Nadu, India, ${ }^{2}$ Department of Pharmacy, Annamalai University, Chidambaram, Cuddalore, Tamil Nadu, India

Email: kalki.vijay@yahoo.co.in

Received: 29 Oct 2018, Revised and Accepted: 12 Dec 2018

\section{ABSTRACT}

Objective: The present study was aimed to enhance the solubility of poorly water-soluble drug (BCS Class II) Febuxostat using water-soluble polymers.

Methods: Pre-formulation studies like drug excipient compatibility studies by Fourier-transform infrared spectroscopyDifferential scanning calorimetry and determination of saturation solubility of drug individually in various media like distilled water and pH 7.4 phosphate buffer. Solid dispersions of Febuxostat was prepared using Polyethylene glycol (PEG 6000) (fusion method) and Polyvinyl pyrrolidone (PVP K30) (solvent evaporation method) in various ratios like 1:1, 1:2, 1:3 and 1:4 separately. The formulated solid dispersions were evaluated for percentage yield, drug content and in vitro dissolution studies.

Results: From the results of pre-formulation studies it was revealed that there was no interaction between drug and excipients and the pure drug was poorly soluble in water. The percentage yield of all formulations was in the range of 54-78 \%, and drug content was in the range of 43-78 mg. The solid dispersion containing polyvinylpyrrolidone $\mathrm{K} 30$ in 1:4 ratio showed the highest amount of drug release at the end of 30 min than other formulations.

Conclusion: Finally it was concluded that solid dispersion prepared with PVP K-30 in 1:4 ratio by solvent evaporation method was more soluble than by fusion method.

Keywords: Febuxostat, Solubility, PEG 6000

(C) 2019 The Authors. Published by Innovare Academic Sciences Pvt Ltd. This is an open access article under the CC BY license (http://creativecommons.org/licenses/by/4.0/) DOI: http://dx.doi.org/10.22159/ijap.2019v11i1.30539

\section{INTRODUCTION}

The solubility/dissolution behavior of a drug is the key factor influencing its oral bioavailability, being the rate-limiting step for absorption of drugs from the gastrointestinal tract. Consequently poor solubility results in low bioavailability increase in the dose, large inter-and intra-subject variation and large variations in plasma drug concentrations under fed versus fasted conditions $[1,2]$.

Dissolution and solubility are two important parameters which alter oral bioavailability of any drug; thus efforts should be done to improve the solubility and dissolution rate is essential. Characteristics of the drugs can be altered by converting them into salt forms, size reduction, and by adding surfactants [3]

Based on the solubility of the drug and its gastrointestinal permeability, they become the fundamental parameters for rate controlling and extent of drug absorption inside the body. The Biopharmaceutics Classification System correlates the in vitro drug dissolution and in vivo bioavailability.

To determine the bioavailability of fast dissolving drugs with high solubility, a simple one point dissolution test and for drugs dissolving slowly, a multiple point dissolution test should be performed which includes low $\mathrm{pH}$, physiological $\mathrm{pH}$, and surfactants so that the in vitro conditions should a mirror as that of the in vivo process $[4,5]$

Solid dispersion refers to a group of solid products consisting of at least two different components, generally a hydrophilic matrix and a hydrophobic drug. The matrix can be either crystalline or amorphous $[6,7]$.

The present study was aimed to enhance the solubility of poorly water-soluble drug (BCS Class II) Febuxostat using water-soluble polymers PEG 6000 and PVP K30.

\section{MATERIALS AND METHODS}

Febuxostat gift sample was obtained from Ranbaxy, Mumbai, Polyethylene glycol 6000 from Borenpharm Co., Ltd, Povidone from
Sigma-Aldrich, Ethanol from Changshu Hongsheng fine chemicals Co., Ltd., Potassium dihydrogen phosphate from Merck Specialties Private Limited, Sodium hydroxide from Lobal Chemie Laboratory Reagents and Fine Chemicals.

Preparation of PH 7.4 phosphate buffer

Potassium dihydrogen phosphate, $0.2 \mathrm{~N}$

About $28.2 \mathrm{~g}$ of potassium dihydrogen phosphate was dissolved in small amount of water and then diluted to $1000 \mathrm{ml}$ with water.

Sodium hydroxide, $0.2 \mathrm{~N}$

About $8 \mathrm{~g}$ of sodium hydroxide was dissolved in small amount of water and then diluted to $1000 \mathrm{ml}$ with water.

\section{pH 7.4 phosphate buffer}

About $50 \mathrm{ml}$ of $0.2 \mathrm{~N}$ potassium dihydrogen phosphate was taken in a $200 \mathrm{ml}$ volumetric flask. To this $39.1 \mathrm{ml}$ of $0.2 \mathrm{~N}$ sodium hydroxide solution was added and diluted to $200 \mathrm{ml}$ with water.

Determination of $\lambda \mathrm{MAX}$ for febuxostat in $\mathrm{PH} 7.4$ phosphate buffer

About $100 \mathrm{mg}$ of Febuxostat was accurately weighed into $100 \mathrm{ml}$ volumetric flask. Volume is made up to $100 \mathrm{ml}$ using pH 7.4 phosphate buffer after dissolving Febuxostat completely. $20 \mathrm{ml}$ was pipetted out from the above solution and diluted to $100 \mathrm{ml}$ using $\mathrm{pH} 7.4$ phosphate buffer. The solution was diluted suitably and scanned in the range of 200-400 nm using UV Spectrophotometer with $\mathrm{pH} 7.4$ phosphate buffer as blank. From the spectrum obtained, the $\lambda$ max for Febuxostat was found to be $315 \mathrm{~nm}$ in $\mathrm{pH} 7.4$ phosphate buffer [8].

\section{Standard graph for febuxostat in PH 7.4 phosphate buffer}

About $100 \mathrm{mg}$ of Febuxostat was accurately weighed into $100 \mathrm{ml}$ volumetric flask. Volume is made up to $100 \mathrm{ml}$ using $\mathrm{pH} 7.4$ phosphate buffer after dissolving Febuxostat completely. This is the primary stock solution, and from this primary stock solution, $20 \mathrm{ml}$ 
was withdrawn and made up to $100 \mathrm{ml}$ with $\mathrm{pH} 7.4$ phosphate buffer. This is called secondary stock solution. From the above solution, 1, 2, 3, 4, 5, 6, 7, 8, 9 and $10 \mathrm{ml}$ was withdrawn and made up to $10 \mathrm{ml}$ with $\mathrm{pH} 7.4$ phosphate buffer separately to produce 2 to $20 \mu \mathrm{g} / \mathrm{ml}$ concentrations respectively. Using UV spectrophotometer the absorbances of these diluted solutions were measured at $\lambda \max$ of $315 \mathrm{~nm}$ with $\mathrm{pH} 7.4$ phosphate buffer as blank. Standard graph of the febuxostat was plotted with concentration $(\mu \mathrm{g} / \mathrm{ml})$ in $\mathrm{x}$-axis and absorbance at $315 \mathrm{~nm}$ in $\mathrm{y}$-axis is shown in.1. The concentrations and its absorbances were subjected to linear regression analysis, and the regression equation was found to be $y=0.044 x-0.058$, and correlation coefficient (r2) was found to be 0.990

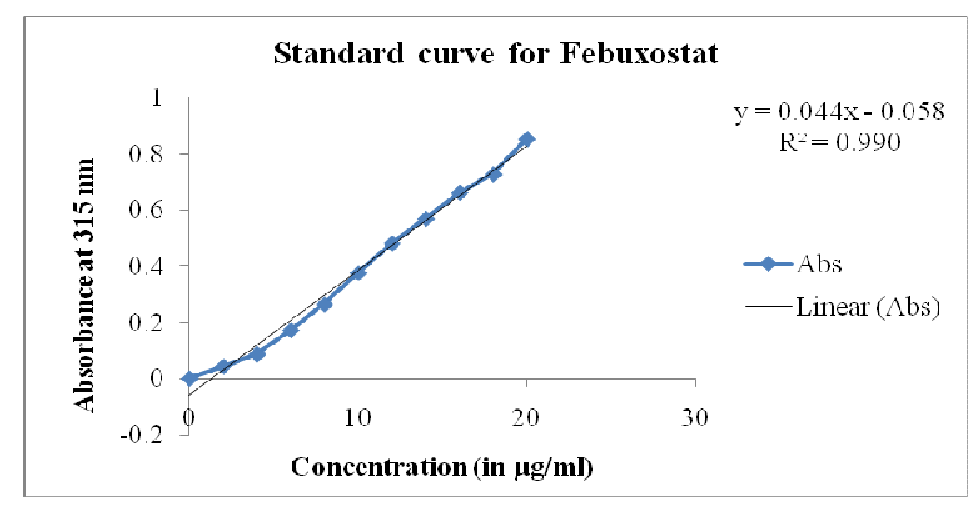

Fig. 1: Standard curve of febuxostat in pH 7.4 phosphate buffer

\section{Pre-formulation studies}

\section{Drug-excipient compatibility studies}

\section{FTIR study}

For all the formulations and Febuxostat, the pellets have been prepared using potassium bromide for FT-IR study. The pellets were subjected to FT-IR instrument 'Perkin Elmer FTIR spectrometer, spectrum 1000 Germany' for the collection of IR spectra which are illustrated in fig. 2 to 4 [9].

\section{Differential scanning colorimeter (DSC) studies}

Differential scanning calorimetry was done by using Differential scanning calorimeter 'PerkinElmer' to obtain the thermograms. Sample after weighing accurately were placed in an aluminum pan and another empty aluminium pan was used as the reference. The scanning was done under nitrogen flow at a scanning rate $10{ }^{\circ} \mathrm{C} / \mathrm{min}$ in range of $30-450{ }^{\circ} \mathrm{C}$. Thermograms were obtained for pure drug, Febuxostat, Polyethylene glycol (PEG) 6000 and Polyvinylpyrrolidone (PVP) K 30 alone and also for combinations of the pure drug with the polymer in 1:1 ratio individually. The results are shown in fig. 5 to 8 .

\section{Determination of saturation solubility}

Using the agitation method, the Solubility study was performed, and saturated solution of Febuxostat was prepared using distilled water and $\mathrm{pH} 7.4$ phosphate buffer and it was stirred for $24 \mathrm{~h}$. The solution filtered through whatmann filter paper $0.45 \mu \mathrm{m}$ after centrifuging for 15 min over 10,000 rpm. The concentration of Febuxostat was determined using UV-visible spectrophotometer against respective solvent as blank at $\lambda \max$ of $315 \mathrm{~nm}$. The results are shown in table 1 .

Table 1: Saturation solubility of febuxostat in various medias

\begin{tabular}{ll}
\hline Name of the media & Saturation solubility of drug (in $\mathbf{~ m g} / \mathbf{m l})$ \\
Distilled water & 0.84 \\
pH 7.4 phosphate buffer & 1.56 \\
\hline
\end{tabular}

\section{Development of solid dispersion}

By fusion method

The solid dispersion of Febuxostat and PEG 6000 prepared in four different weight ratios $(1: 1,1: 2,1: 3$ and 1:4) and denoted as FF1,
FF2, FF3 and FF4, respectively. With constant stirring Febuxostat was added to molten PEG 6000 and resulting homogenous dispersion was allowed to solidify. The solid dispersion thus formed was ground in the mortar and sieved to produce uniform particle size dispersion. Formulation codes are shown in table 2.

Table 2: Formula for the preparation of solid dispersion of febuxostat with different polymers

\begin{tabular}{llll}
\hline Formulation code & Formulation & Carrier & Drug: carrier \\
\hline FF1 & & & $1: 1$ \\
FF2 & Solid Dispersion & PEG 6000 & $1: 2$ \\
FF3 & & & $1: 3$ \\
FF4 & & $1: 4$ \\
FF5 & & $1: 1$ \\
FF6 & Solid Dispersion & PVP K 30 & $1: 2$ \\
FF7 & & & Fusion method \\
FF8 & & & $1: 3$ \\
\hline
\end{tabular}

\section{By solvent evaporation method}

Solid dispersion of Febuxostat and PVP K-30 were prepared in four different weight ratios $(1: 1,1: 2,1: 3$ and 1:4) and denoted as FF5, FF6, FF7 and FF8, respectively. The required quantity of PVP K-30 was dissolved in ethanol and to this Febuxostat was added. The resulting solution was then homogenized thoroughly and evaporated the solvent. Complete removal of solvent was achieved by drying the mass obtained in the oven at $40^{\circ} \mathrm{C}$ for $24 \mathrm{~h}$.

The produced. Solid dispersion was then ground, sieved and kept for further analysis. Formulation codes are shown in table 2. 


\section{Characterization of solid dispersion}

\section{Determination of percentage yield}

Percentage yield was calculated for each batches of solid dispersion with respect to theoretical yield and practical yield. The results are shown in table 3 .

Percentage yield - (Practical yield /Theoretical yidld $) \times 100$

\section{Estimation of drug content in solid dispersion}

Sample containing $50 \mathrm{mg}$ of prepared solid dispersion was accurately weighed and dissolved in freshly phosphate buffer $\mathrm{pH} 7.4$ in a $100 \mathrm{ml}$ volumetric flask. The volume was made up to $100 \mathrm{ml}$ with phosphate buffer $\mathrm{pH}$ 7.4. The absorbance of the resulting solution was measured at $315 \mathrm{~nm}$ for Febuxostat, against blank (phosphate buffer $\mathrm{pH}$ 7.4) using UV spectrophotometer. The results are shown in table 3 .

\section{In vitro dissolution rate studies on solid dispersions}

The In vitro dissolution for the prepared solid dispersions was performed using Labindia Disso 2000 dissolution test apparatus.
Solid dispersions equivalent to $100 \mathrm{mg}$ of Febuxostat were filled in empty hard gelatin capsules were placed in $900 \mathrm{ml}$ of $\mathrm{pH} 7.4$ phosphate buffer as dissolution medium. The speed was maintained at $50 \mathrm{rpm}$ using the paddle for $30 \mathrm{~min}$. The temperature of the dissolution medium was maintained constant at $37 \pm 0.5{ }^{\circ} \mathrm{C}$ throughout the study. Samples of about $10 \mathrm{ml}$ were pipette out at regular time intervals at 10,20 and $30 \mathrm{~min}$. The sink condition was maintained by replacing with an equal volume of fresh dissolution medium. The withdrawn aliquots were filtered through whatmann filter paper $0.45 \mu$, suitably diluted and assayed for Febuxostat at $315 \mathrm{~nm}$ using UV spectrophotometer. The dissolution experiments were conducted in triplicate. The results are shown in fig. 9 [10].

\section{RESULTS AND DISCUSSION}

\section{Pre-formulation studies}

\section{Drug-excipient compatibility studies (FTIR)}

The FTIR studies were shown in fig. 2 to 4 . From the results of preformulation studies, it was revealed that there no chemical incompatibility between drug and excipients from FTIR studies.

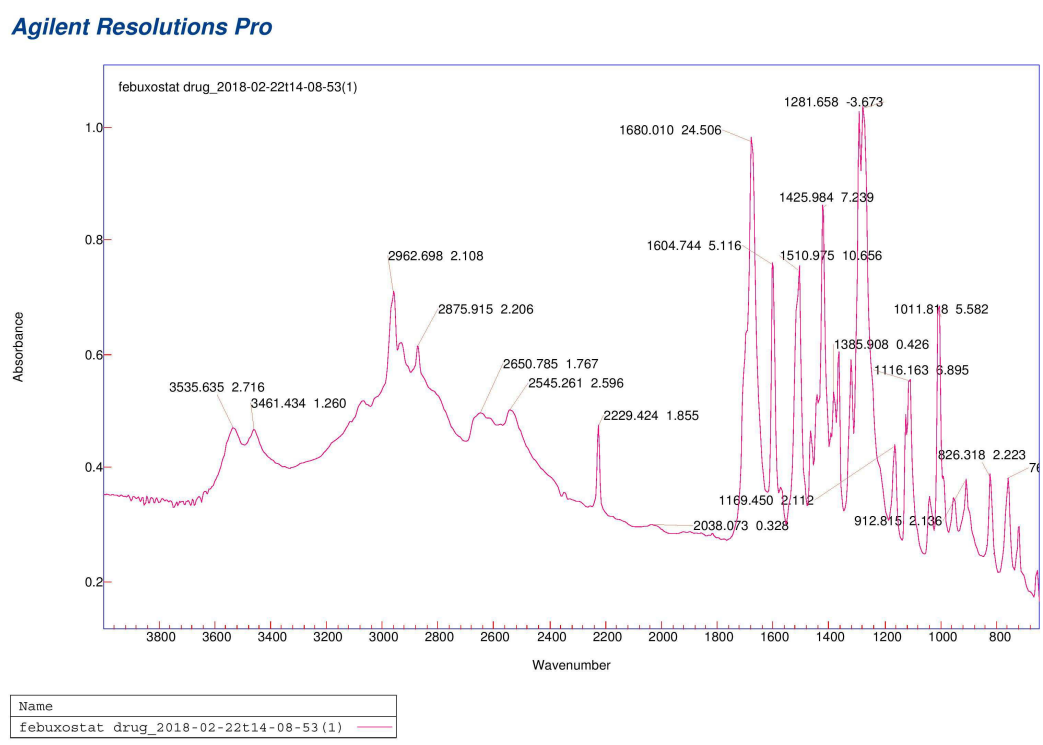

Fig. 2: FTIR for febuxostat

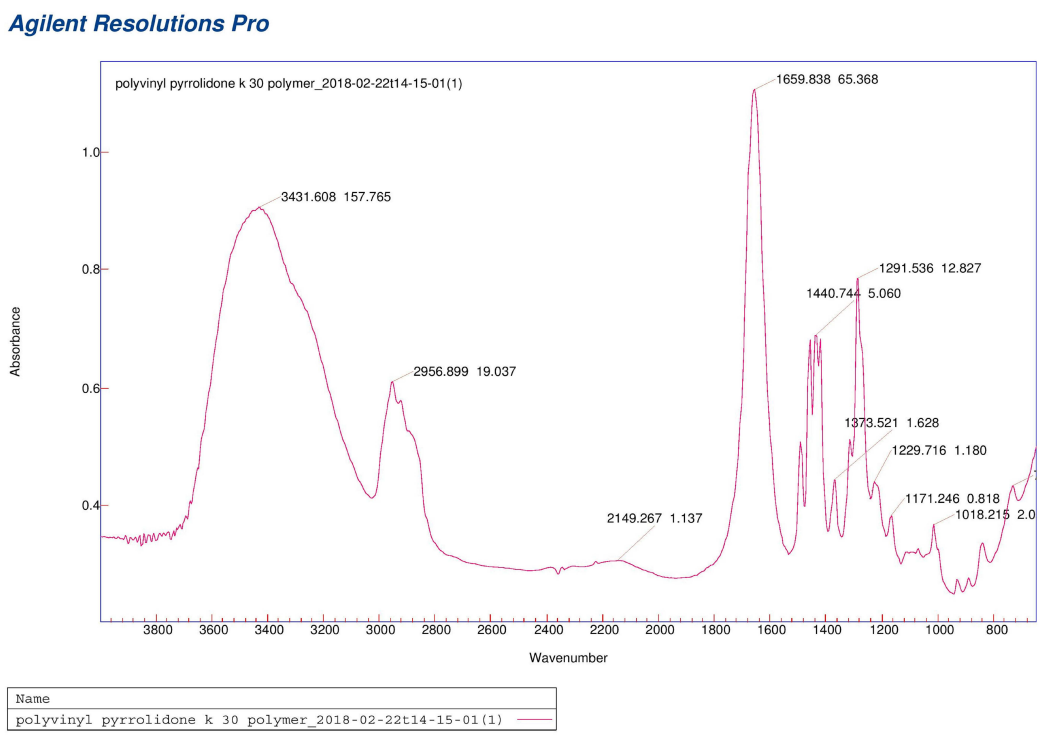

Fig. 3: FTIR for povidone 


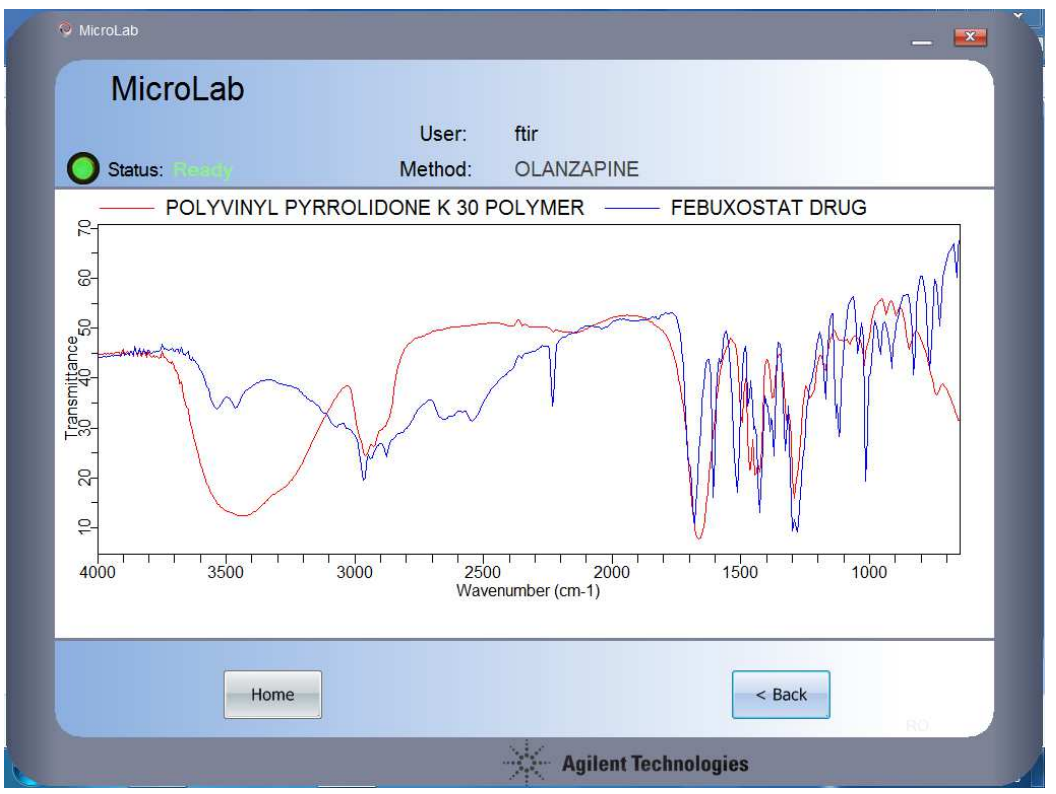

Fig. 4: FTIR for febuxostat with povidone

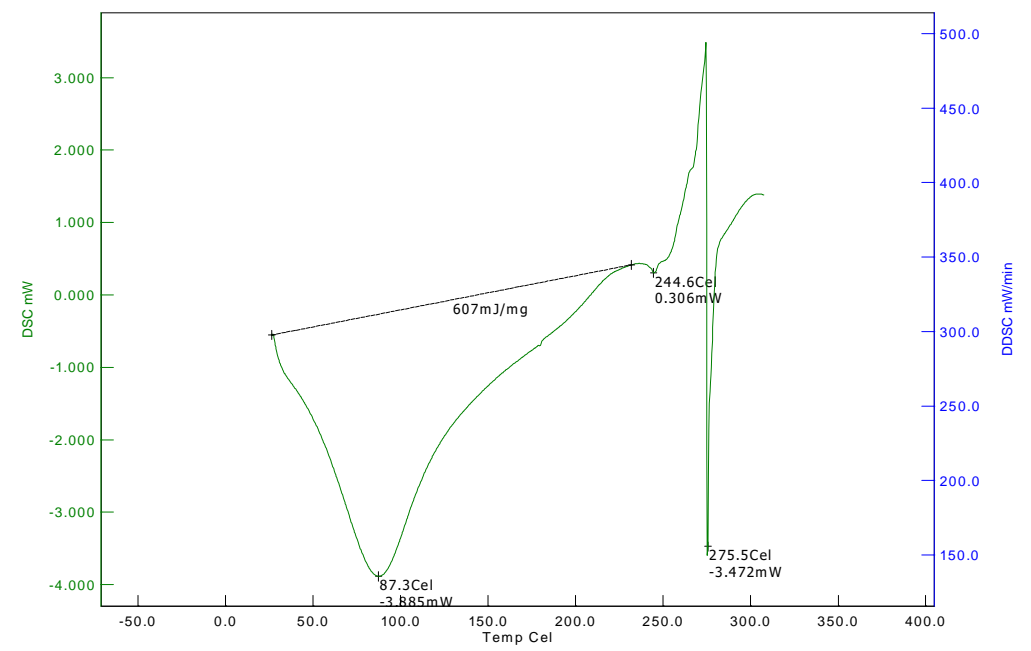

Fig. 5: DSC thermogram for febuxostat

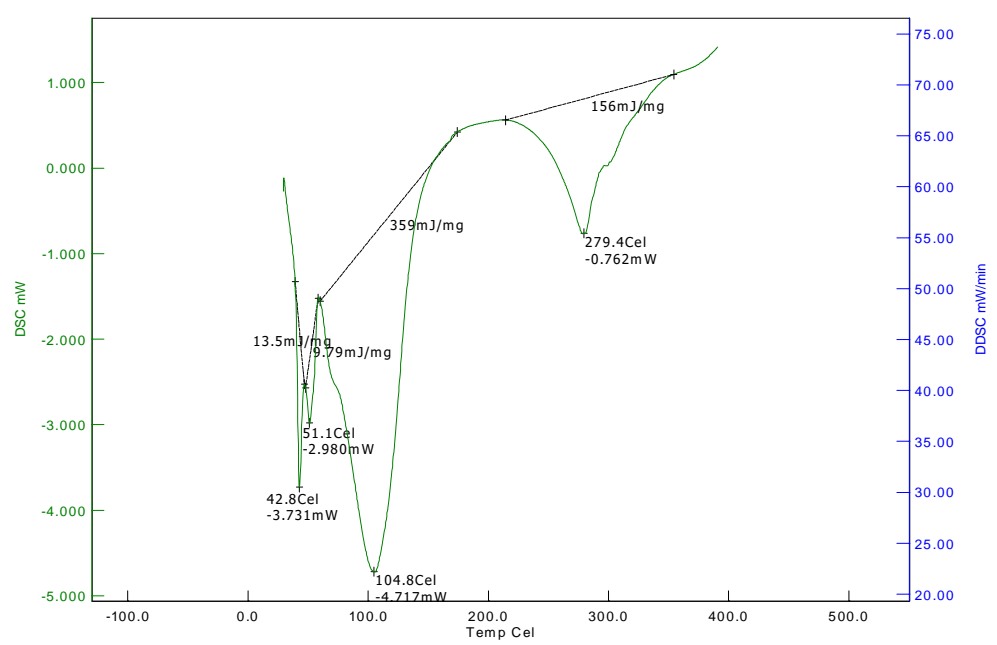

Fig. 6: DSC thermogram for febuxostat with polymer in 1:1 ratio 


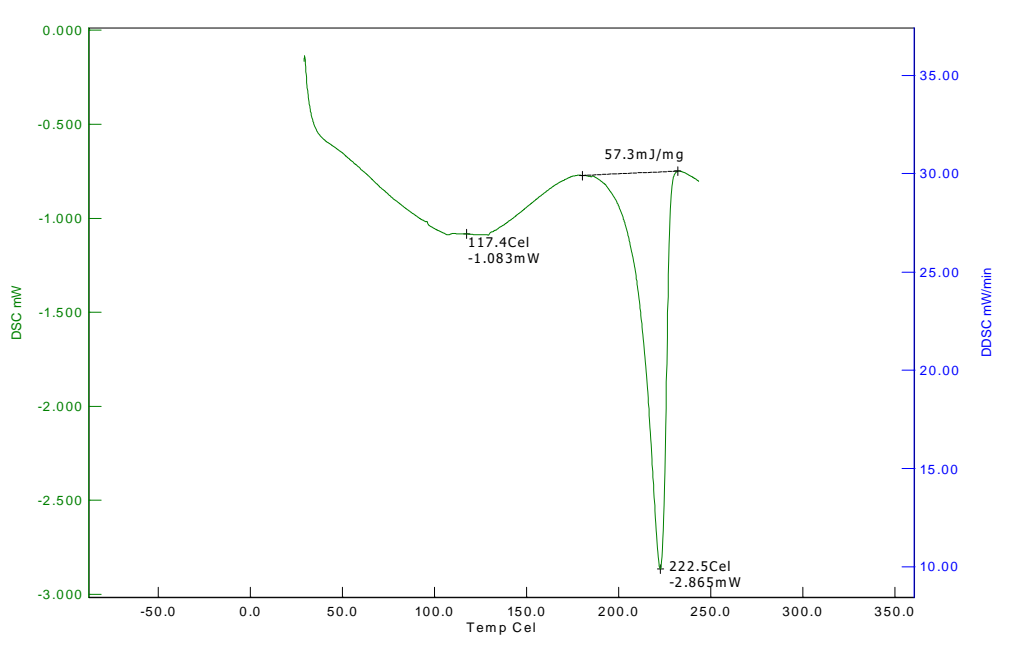

Fig. 7: DSC thermogram for PEG 6000

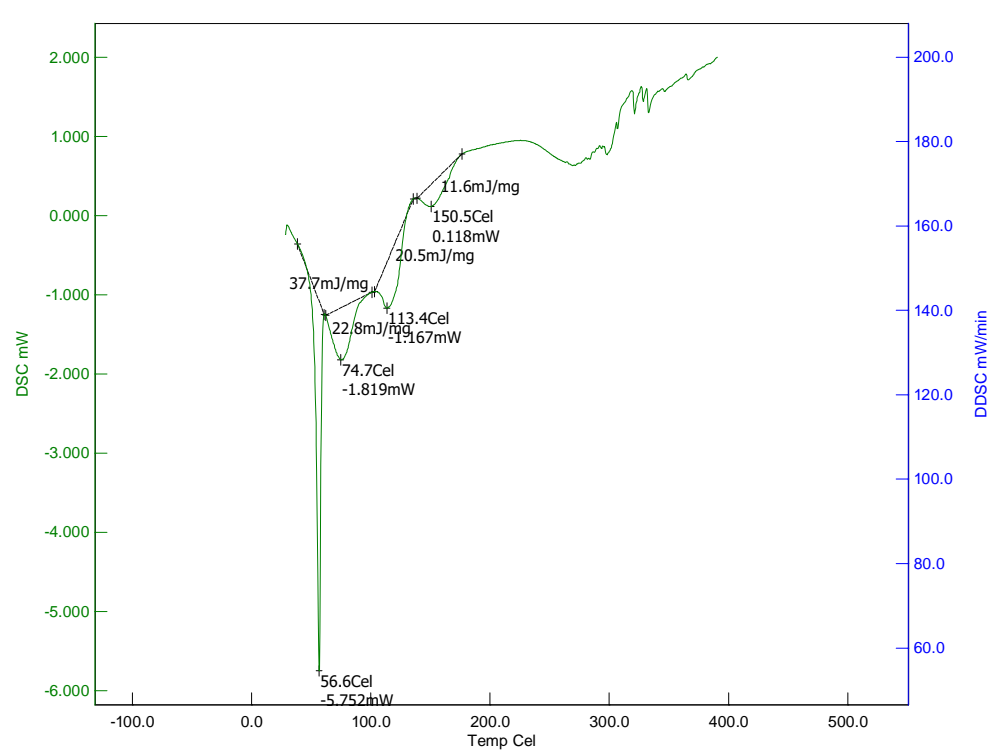

Fig. 8: DSC thermo gram for povidone

\section{Drug-excipient compatibility studies (DSC)}

The DSC thermogram shown in fig. 5 to 8 , there was a sharp endotherm peak at $87^{\circ} \mathrm{C}$ and $275^{\circ} \mathrm{C}$ which was shifted to $104{ }^{\circ} \mathrm{C}$ and $279{ }^{\circ} \mathrm{C}$ when it is combined with the polymer at 1:1 ratio. From the results of preformulation studies, it was revealed that there no chemical incompatibility between drug and excipients from DSC studies.

\section{Determination of saturation solubility}

The saturation solubility studies is shown in table no. 1. It is found that the solubility of Febuxostat was higher in $\mathrm{pH} 7.4$ phosphate buffer than water. So, pH 7.4 phosphate buffer was chosen as dissolution media for in vitro dissolution studies.

\section{Characterization of solid dispersion}

Table 3: Characterization of solid dispersion of febuxostat

\begin{tabular}{lll}
\hline Formulation code & Percentage yield (\% w/w) & Drug content (mg) \\
\hline FF1 & 58 & 43 \\
FF2 & 64 & 48 \\
FF3 & 78 & 45 \\
FF4 & 71 & 51 \\
FF5 & 54 & 64 \\
FF6 & 68 & 59 \\
FF7 & 54 & 62 \\
FF8 & 74 & 78 \\
\hline
\end{tabular}




\section{Determination of percentage yield}

The percentage yield for various ratios of different drug and polymer were calculated and shown in table 3 . The results revealed that the percentage yield was high in 1:4 ratio solid dispersion prepared by solvent evaporation method than compared to the fusion method.

\section{Estimation of drug content in solid dispersion}

The drug content for various ratios of different drug and polymer were calculated and shown in table 3 . The results revealed that the drug content was high in 1:4 ratio solid dispersion prepared by solvent evaporation method than compared to the fusion method.

\section{In vitro dissolution rate studies on solid dispersions}

In vitro dissolution study was carried out with solid dispersions prepared by various methods in various ratios are given in fig. 9 . From the results obtained, the percentage drug released at the end of $30 \mathrm{~min}$ was found to be high in solid dispersion containing PVP K30 (1:4 ratio) than other solid dispersion of PVP K30 and PEG 6000 in various ratios which may be due to increased entrapment of drug in solvent evaporation method than fusion method.

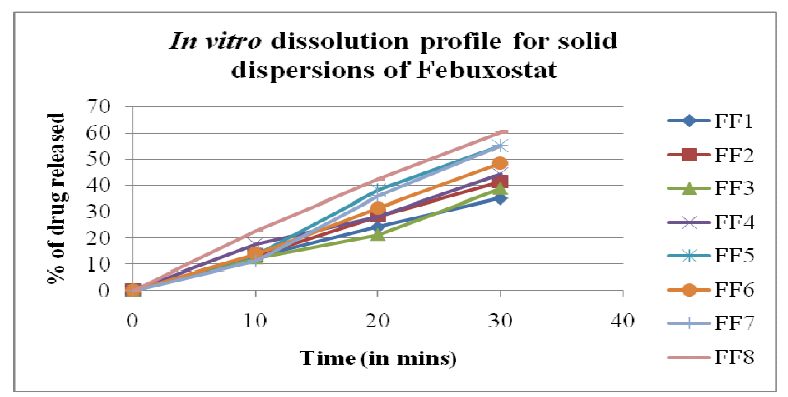

Fig. 9: In vitro dissolution profile for solid dispersions of febuxostat (Results are expressed as mean $\pm S D, n=3$ )

\section{CONCLUSION}

Febuxostat is a xanathine oxidase inhibitor indicated in patients with gout suffering from hyperuricemia and is used in its chronic management has low bioavailability when given orally because it is a poorly water-soluble drug with a plasma elimination half-life of 5-8 h. We conclude that the present study of the formulation development for the BCS Class II drug Febuxostat by solvent evaporation method was better than Fusion method in the 1:4 ratio were increase the solubility and dissolution rate.

\section{AUTHORS CONTRIBUTIONS}

All the authors have contributed equally

\section{CONFLICT OF INTERESTS}

Declared none

\section{REFERENCES}

1. Mohini SP, Sheetal ZG, Saudagar RB. Solubility enhancement by various techniques: an overview. World J Pharm Pharm Sci 2013;2 Suppl 6:4558-72.

2. Chaturvedi AK, Verma A. Solubility enhancement of poorly water-soluble drugs by solid dispersion. Int J Pharm Sci Res 2011;3 Suppl 1:26-34.

3. Nikita Sehgal, Vishal Gupta N, Gowda DV, Praveen Sivadasu. Fabrication and evaluation of solid dispersion containing glibenclamide. Asian J Pharm Clin Res 2018;11 Suppl:158-61.

4. Gordon LA, Lennernas H, Vinod PS, John RC. A theoretical basis for a biopharmaceutic drug classification: the correlation of in vitro drug product dissolution and in vivo bioavailability. Pharm Res 1995;12 Suppl 3:413-20.

5. Mogal SA, Gurjar PN, Yamgar DS, Kamod AC. Solid dispersion technique for improving solubility of some poorly soluble drugs. Der Pharm Lett 2012;4 Suppl 5:1574-86.

6. Sareen S, Mathew G, Joseph L. Improvement insolubility of poor water-soluble drugs by solid dispersion. Int J Pharm Investig 2012;2 Suppl 1:12-7.

7. Jatinder Kaur, Geeta Aggarwal, Gurpreet Singh, Rana AC. Improvement of drug solubility using solid dispersion. Int J Pharm Pharm Sci 2012;4 Suppl 2:47-53.

8. Indian Pharmacopoeia. The Indian Pharmacopoeia Commission, Ghaziabad. $7^{\text {th }}$ ed; 2014;1:757-8.

9. Tripathy S, Sharma PK, Banthia AK. Preparation, characterization, in vitro and in vivo evaluation of aceclofenac ointment. Indian J Pharm Sci 2005;42 Suppl 9:618-20.

10. Asija R, Bhatt S, Sangeetaasija, Shah I, Yadav A. Solubility enhancement of nebivolol by solid dispersion technique. Asian J Pharm Tech 2014;4 Suppl 3:134-40. 